\title{
Watermelon Stomach Seen \\ by Wireless-Capsule Endoscopy
}

M. Mascarenhas-Saraiva, L. Lopes,

A. Mascarenhas-Saraiva

Digestive Endoscopy and Motility Unit, Trindade Hospital, Porto, Portugal

\section{Corresponding Author}

M. Mascarenhas-Saraiva, M.D., Ph.D.

Digestive Endoscopy and Motility Unit Trindade Hospital

Rua Trindade 115

4000-541 Porto

Portugal

Fax: $\quad+351-22-3390-732$

E-mail: miguelms@manoph.pt

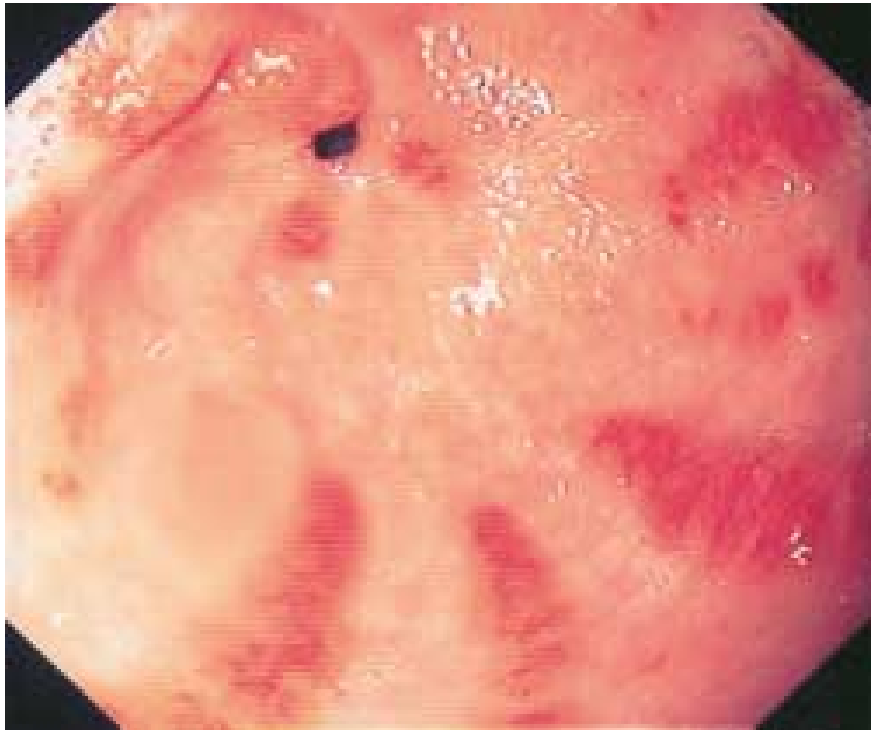

Figure 1 A 51-yearold man with iron-deficiency anemia underwent an upper digestive endoscopy which revealed a watermelon stomach, i. e. linear red streaks running longitudinally in the gastric antrum.

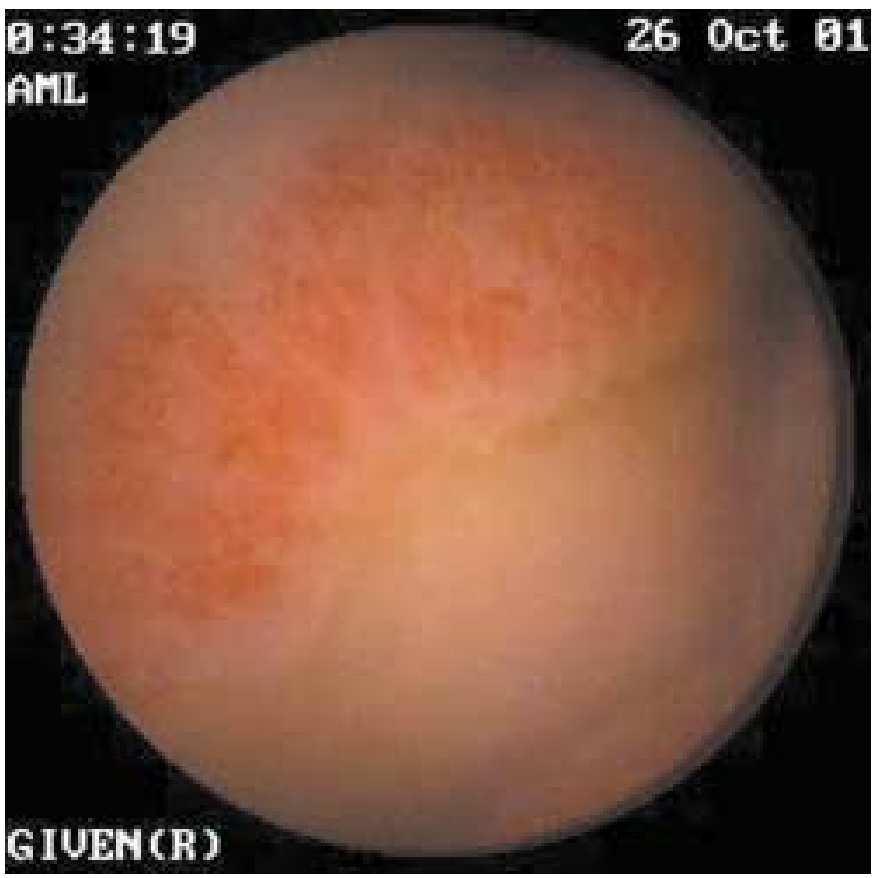

Figure 2 To evaluate concomitant sources of bleeding, ileocolonoscopy and wireless-capsule endoscopy were performed. lleocolonoscopy showed normal findings. Capsule endoscopy showed linear red streaks in the stomach running longitudinally in the gastric antrum, as was expected; in the jejunum there were two small angiodysplasias. This is the first image of a watermelon stomach seen by wireless-capsule endoscopy. All the red streaks were coagulated using argon plasma, in a single session. 